\title{
Adding a modified Lemaire procedure to ACLR in knees with severe rotational knee instability does not compromise isokinetic muscle recovery at the time of return-to- play
}

Leopold Joseph', Guillaume Demey ${ }^{1}$, Thomas Chamu², Axel Schmidt ${ }^{3}$, Alexandre Germain², Floris van Rooij ${ }^{4^{*}}$ (D) Mo Saffarini ${ }^{4}$ and David Dejour ${ }^{1}$

\begin{abstract}
Purpose: To determine whether isokinetic muscle recovery following ACLR using a hamstring tendon (HT) would be equivalent (non-inferior) in knees that had high-grade pivot-shift and adjuvant modified Lemaire procedure versus knees that had minimal pivot-shift and no adjuvant modified Lemaire procedure.

Methods: We evaluated 96 consecutive patients that underwent primary ACLR. Nine were excluded because of contralateral knee injury, and of the remaining 87, ACLR was performed stand-alone in 52 (Reference group), and with a Lemaire procedure in 35 (Lemaire group) who had high-grade pivot-shift, age $<18$, or genu recurvatum $>20^{\circ}$. At 6 months, isokinetic tests were performed at $240^{\circ} / \mathrm{s}$ and $90 \%$ to calculate strength deficits of hamstrings $(\mathrm{H})$ and quadriceps (Q). At 8 months, patients were evaluated using IKDC, Lysholm, and Tegner scores.

Results: Compared to the Reference group, the Lemaire group were younger $(23.0 \pm 2.5$ vs $34.2 \pm 10.5, p=0.021)$ with a greater proportion of males ( $80 \%$ vs $56 \%, p<0.001)$. The Lemaire group had no complications, but the Reference group had one graft failure and one cyclops syndrome. Strength deficits at $240 \%$ and at $90 \%$ were similar in both groups, but mixed H/Q ratios were lower for the Lemaire group (1.02 \pm 0.19 vs $1.14 \pm 0.24, p=0.011)$. IKDC and Lysholm scores were similar in both groups, but Tegner scores were higher in the Lemaire group (median, 6.5 vs 6.0, $p=0.024$ ).
\end{abstract}

Conclusions: ACLR with a modified Lemaire procedure for knees with rotational instability grants equivalent isokinetic muscle recovery as stand-alone ACLR in knees with no rotational instability. For ACL-deficient knees with high-grade pivot-shift, a Lemaire procedure restores rotational stability without compromising isokinetic muscle recovery.

Study design: Level III, comparative study.

Keywords: Anterior cruciate ligament reconstruction, Isokinetic tests, Lemaire procedure, Anterolateral complex, Pivot-shift

\footnotetext{
*Correspondence: journals@resurg.com

${ }^{4}$ ReSurg SA, Rue Saint Jean 22, 1260 Nyon, Switzerland

Full list of author information is available at the end of the article
}

\section{Springer Open}

(0) The Author(s). 2020 Open Access This article is licensed under a Creative Commons Attribution 4.0 International License, which permits use, sharing, adaptation, distribution and reproduction in any medium or format, as long as you give appropriate credit to the original author(s) and the source, provide a link to the Creative Commons licence, and indicate if changes were made. The images or other third party material in this article are included in the article's Creative Commons licence, unless indicated otherwise in a credit line to the material. If material is not included in the article's Creative Commons licence and your intended use is not permitted by statutory regulation or exceeds the permitted use, you will need to obtain permission directly from the copyright holder. To view a copy of this licence, visit http://creativecommons.org/licenses/by/4.0/. 


\section{Introduction}

Anterior cruciate ligament tears are often aggravated by concomitant injuries of the anterolateral complex that increase the rotational instability of the knee $[5,8,22,25]$. If left untreated, anterolateral complex injuries could compromise outcomes of anterior cruciate ligament reconstruction (ACLR), particularly risks of re-tear or subsequent meniscal injury in patients returning to pivoting sports [19].

Several techniques have been described for lateral extra-articular tenodesis (LET) of the anterolateral complex, for which the indications continue to evolve [16], the present consensus being patients aged under 30 and/ or that have concomitant medial meniscus tears [6, 35]. The Lemaire procedure, popularised in the 1980s [26], with variants by Christel and Djian [7], as well as Ntagiopoulos and Dejour [35], proved effective in ACLR in terms of biomechanics [33], safety [36], and reproducibility [35]. This procedure has shown benefits in patients with high risks of re-tear or those participating in pivoting sports [16, 27], by limiting translation within the lateral compartment $[15,27,39,47]$, reducing pivot-shift $[16,30,32,47]$, and protecting the graft and meniscus $[17,18,30]$, with little or no side effects [36].

Isokinetic evaluation of muscle strength recovery is becoming one of the primary tools to evaluate the safety of return-to-play (RTP) after ACLR $[10,11]$. To the authors' knowledge there are no published studies that evaluated muscle recovery at the time of RTP following ACLR with Lemaire extra-articular tenodesis. The purpose of this study was therefore to determine whether isokinetic muscle recovery following ACLR using a hamstring tendon (HT) would be equivalent (non-inferior) in knees that had high-grade pivot-shift and adjuvant modified Lemaire procedure versus knees that had minimal pivot-shift and no adjuvant modified Lemaire procedure. The hypothesis was that an extra-articular modified Lemaire procedure restores rotational stability of the knee without increasing isokinetic muscle deficit at the time of RTP.

\section{Methods}

\section{Study design}

The authors retrospectively collected the records of 96 consecutive patients that underwent primary ACLR using HT autografts, with a Lemaire procedure (Lemaire group) or without a Lemaire procedure (Reference group), between March 2016 and May 2018 at a single center. All patients had subjective instability and functional impairment, confirmed by a positive Lachman test and/or pivot-shift test (PST). The decision to perform to a modified Lemaire procedure was discussed with the patients in advance and was based primarily on the following indications: clunk or gross PST, patient aged under 18 years, or $>20^{\circ}$ genu recurvatum. Patients that had severe concomitant ligament injury $(n=0)$ or history of intra- or extra- articular surgery on the ipsi- or contralateral knee $(n=9)$ were excluded from this study (Fig. 1). This left a cohort of 87 patients, all of whom provided written informed consent for the use of their data and images for research and publishing purposes. This study was also approved by the institutional review board in advance (COS-RGDS-2020-03-006-DEJOURD).

\section{Clinical assessment}

The following clinical assessment was performed preand post-operatively: The International Knee Documentation Committee (IKDC) functional score [23], Lysholm knee scale [28], and Tegner activity score [41] were recorded by an independent clinician. Anterior Cruciate Ligament-Return to Sport after Injury (ACL-RSI) scale [3] was also assessed post-operatively. Anteroposterior knee laxity was assessed using 'static' and 'dynamic' measurements of anterior tibial translation (ATT) on 'true lateral view' radiographs, superimposing the posterior femoral condyles. The ATT was defined as the distance between two lines parallel to the posterior tibial cortex: the first tangent to the posterior aspect of the medial tibial plateau, and the second tangent to the posterior femoral condyles [12, 35], Static ATT was measured on monopodal weight bearing radiographs with the knee flexed at $20^{\circ}$. Dynamic ATT was measured using the Telos $^{\text {Ts }}$ stress radiography device (Metax, Hungen, Germany) with a constant anterior force of $150 \mathrm{~N}$, and the side-to-side difference between the injured knee and healthy knee was calculated. A side-to-side difference of $9 \mathrm{~mm}$ was considered a complete ACL rupture [13]. Rotational laxity was determined with the PST by the senior surgeon (DHD), by applying a valgus force to the tibia in internal rotation while flexing the knee from full extension. The results were assessed using the criteria of the IKDC as none $(0)$, glide $(+1)$, clunk $(+2)$ or gross $(+$ $3)$. The PST was considered high-grade if it indicated clunk or gross. Meniscal and ligament tears were assessed on magnetic resonance images (MRI).

\section{Surgical technique}

All operations were performed under general anesthesia with a tourniquet placed high on the thigh. The graft was harvested from the hamstrings to form a 4-strand configuration using the gracilis and semitendinosus, which were left attached on their tibial insertions then doubled and sutured together to achieve appropriate length and thickness for the size of the patient. Meniscal tears and ligament status were further confirmed arthroscopically, by direct vision and palpation with a probe, at the time of ACL reconstruction. Meniscal treatments were performed when necessary, either by 


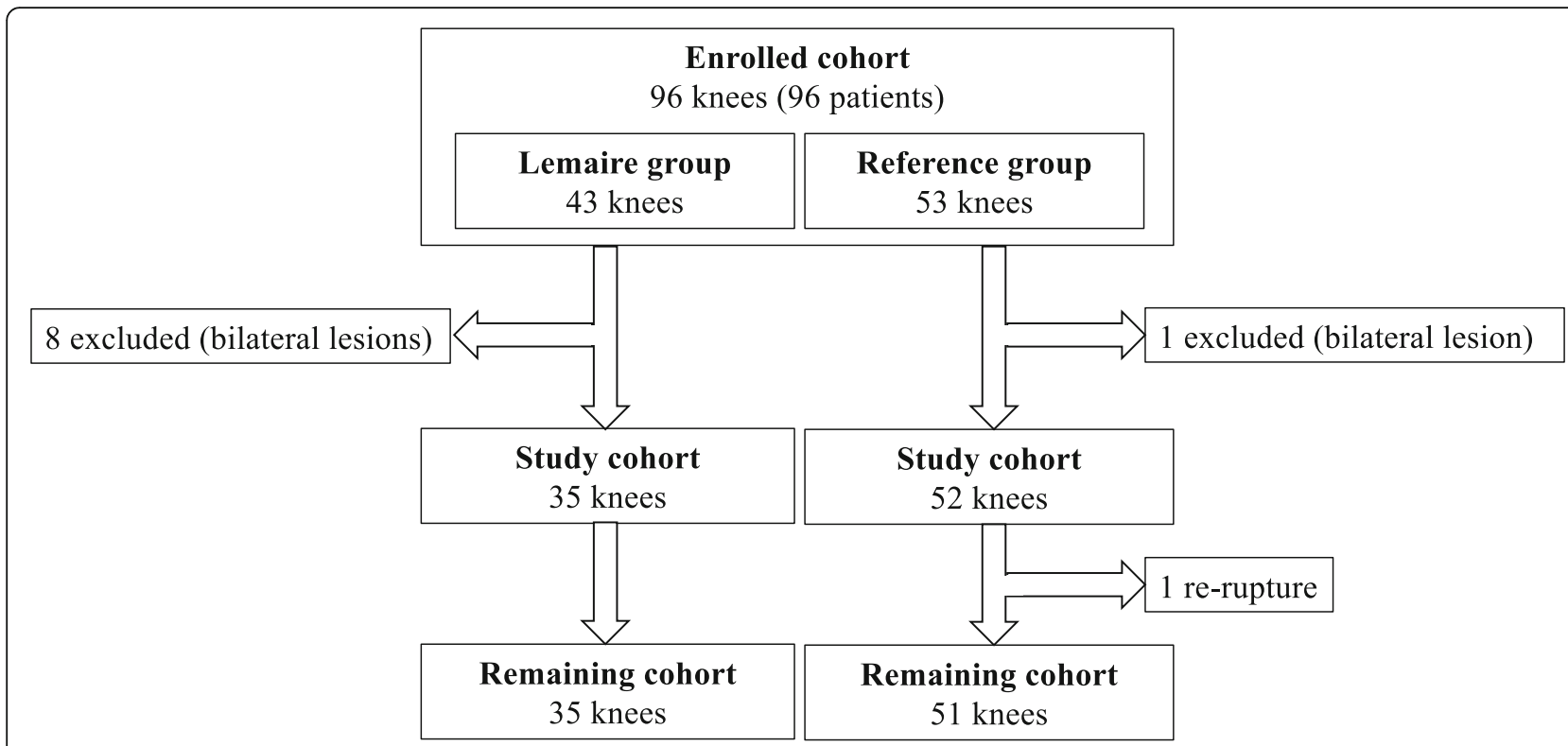

Fig. 1 Flowchart

suture repair (Fast-Fix 360, Smith\&Nephew, Memphis, $\mathrm{TN}$ ) in stable lesions in zone 0 or 1 or by partial meniscectomy in unstable lesions or in those in zones 2 or 3 [9]. The femoral tunnel preparation was performed using an outside-in guide for femoral tunnel placement. For the tibial tunnel, a standard $55^{\circ}$ angulation guide was used. The graft was passed from the tibia to the femur and fixed with Ligafix interference screws (SBM, Lourdes, France), with a composition of tri-calcium phosphate (TCP) of $30 \%$ for femoral tunnel screws and of $60 \%$ for tibial tunnel screws.

The modified Lemaire procedure was performed in 35 knees using the following method [35]. The knee was prepared and draped in the $90^{\circ}$ flexed position (Fig. 2). The iliotibial band (ITB) was identified and incised to create a $10 \mathrm{~mm} \times 80 \mathrm{~mm}$ strip originating from Gerdy's tubercle (GT). It was proximally sectioned, and whip stitched. The ITB graft was then passed under the lateral collateral ligament (LCL), in a tunnel separate to that of the ACLR graft, at the isometric point. The ITB graft was then fixed with an absorbable interference screw of a constant diameter of $7 \mathrm{~mm}$ (SBM, Lourdes, France).

\section{Postoperative rehabilitation}

The rehabilitation protocol was divided into three phases:

Phase 1 (0-6 weeks): The ROM goals were to obtain full extension and $90^{\circ}$ of flexion at 3 weeks, then $120^{\circ}$ of flexion at 6 weeks. Partial weight-bearing (50\% body weight) was allowed during the first 3 postoperative weeks if the preoperative static ATT was $<5 \mathrm{~mm}$, [14] and progressive full weight-bearing was allowed between 3 and 6 weeks.
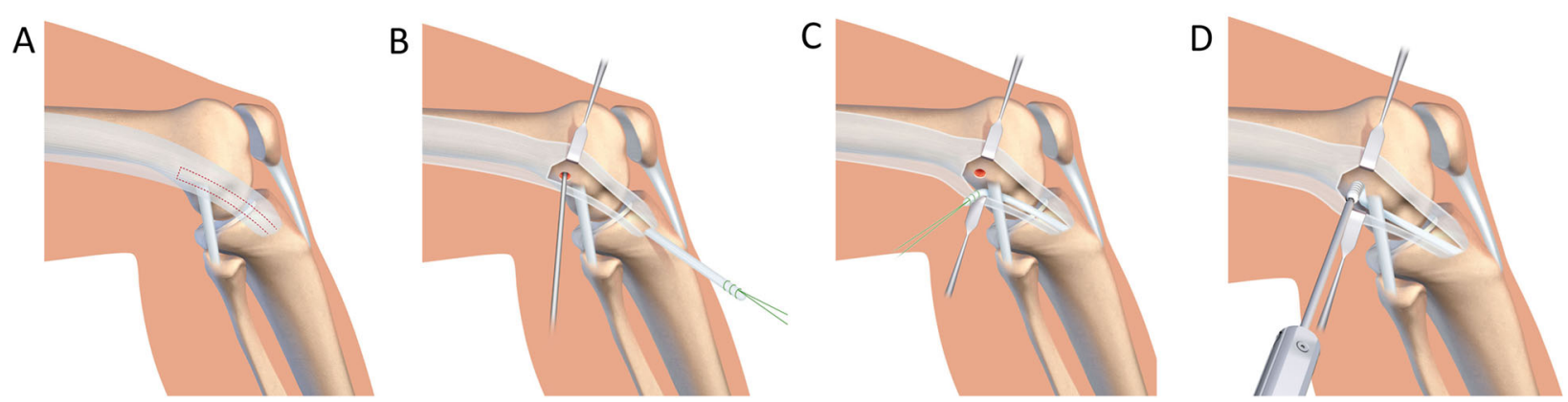

Fig. 2 a The iliotibial band (ITB) was identified and incised to create a $10 \mathrm{~mm} \times 80 \mathrm{~mm}$ strip originating from Gerdy's tubercle (GT). b It was proximally sectioned, and whip stitched. $\mathbf{c}$ The ITB graft was then passed under the lateral collateral ligament (LCL), in a tunnel separate to that of the ACLR graft, at the isometric point. $\mathbf{d}$ The ITB graft was then fixed with an absorbable interference screw of a constant diameter of $7 \mathrm{~mm}$ 
Phase 2 (6-12 weeks): The aims were to get full ROM, increase muscular strength and knee stability. At the end of this phase, the patient was expected to walk quickly and climb stairs.

Phase 3 (3-8 months): The aim was to regain the normal muscle strength and gradual return to sport. This phase consisted of heavy resistance strength training and exercises depending on type of sport practiced.

\section{Isokinetic tests}

Isokinetic tests were performed by 2 physiotherapists (TC, AG), blinded to the study design, at 6-8 months follow-up, as part of a rehabilitation program to enable patients to achieve specific goals for return to sport at 9-12 months. The tests were performed using a CONTREX system (Physiomed, Schnaittach, Germany) at the same rehabilitation center following a standardized protocol. The CON-TREX isokinetic dynamometer has demonstrated moderate-to-high reliability for both the knee extensor and the flexor muscle groups [29]. The patients warmed up using an ergometric bicycle for 15 min prior to the isokinetic tests. The subject was then seated on the dynamometer, stabilized by thoracic and lumbar straps, with a short tibial support on the tested leg, and a fixed contralateral leg. Testing started with the contralateral side to determine speed and amplitude.

Adequate preparation was done at submaximal intensity to familiarize patients, in concentric mode, to gain appreciation of the speeds and verify the patients' understanding of the exercise. The first test was performed assessing the hamstrings and quadriceps muscle groups both in concentric and eccentric mode at an amplitude of $20^{\circ}-90^{\circ}$ of flexion completing 3 repetitions at $90^{\circ} / \mathrm{s}$ and 15 repetitions at $240 \%$ [20]. Between every test there was a rest period of $90 \mathrm{~s}$. The second test was performed assessing the hamstrings at an amplitude of $90^{\circ}$ $20^{\circ}$ of flexion completing 3 repetitions at $30^{\circ} / \mathrm{s}$ in eccentric mode to evaluate recovery of the hamstring tendons. The percentage deficits of the healthy side compared to the contralateral side were collected for each muscle group (hamstrings, H; quadriceps, Q) and each angular velocity. The $\mathrm{H} / \mathrm{Q}$ ratios were calculated for concentric strength at $240 \% \mathrm{~s}$ and at $90 \% \mathrm{~s}$, as well as mixed speeds (H30/Q240), since they closely represent the biomechanics of athletes during sports [10].

\section{Statistical analysis}

An a priori sample size calculation for the principal goal of the study indicated that 35 patients per group were needed to detect a minimal clinically important difference in isokinetic ratios of $5.75 \%$ [2] with a standard deviation (SD) of $11 \%$ and a statistical power of 0.80 . The Shapiro-Wilk test was used to verify normality of distributions. Continuous variables were compared using unpaired t-tests or Mann-Whitney tests. Categorical variables were compared using Chi-square tests or Fisher's exact tests. Statistical analyses were performed using $\mathrm{R}$ version 3.5.2 (R Foundation for Statistical Computing, Vienna, Austria). $P$ values $<0.05$ were considered statistically significant.

\section{Results}

Of the initial cohort of 87 patients, 1 underwent revision surgery due to graft failure, leaving a final cohort of 86 patients, of which 35 were in the Lemaire group and 51 were in the Reference group (Table 1). Patients in the Lemaire group were younger $(23.0 \pm 2.5$ years vs $34.2 \pm$ 10.5 years, $p=0.021$ ) with a greater proportion of males ( $80 \%$ vs $56 \%, p<0.001$ ), and had a significantly better flexion range $(p=0.022)$, even though 1 patient only had $60^{\circ}$ of flexion. The two groups had a similar prevalence of meniscal lesions $(p=0.368)$ and types of meniscal treatments $(p=0.711$ and $p=0.599)$ (Table 2). None of the patients in the Lemaire group experienced complications, while one patient in the Reference group experienced a cyclops syndrome (treated by arthroscopic debridement).

\section{Isokinetic scores}

In concentric mode the hamstrings deficit was similar among the two groups at $240^{\circ} / \mathrm{s}(9.0 \% \pm 16.6$ vs $10.9 \% \pm$ $16.6, p=0.910)$ and at $90 \%(\mathrm{~s}(9.0 \% \pm 13.6$ vs $8.5 \% \pm 22.4$, $p=0.993$ ), while the quadriceps deficit was smaller in the Lemaire group than the Reference group at $240 \% \mathrm{~s}$ $(13.6 \pm 12.2$ vs $18.2 \pm 13.4, p=0.127)$ and at $90^{\circ} / \mathrm{s}(12.2 \pm$ 15.9 vs $15.6 \pm 14.1, p=0.141$ ) (Table 3 ). The only significant difference was the mixed $\mathrm{H} / \mathrm{Q}$ ratio which was lower in the Lemaire group than in the Reference group $(1.02 \pm 0.19$ vs $1.14 \pm 0.24, p=0.011)$.

\section{Clinical outcomes}

Lysholm, IKDC and ACL-RSI were similar among the two groups (Table 4). Tegner scores were however higher for the Lemaire group than the Reference group (median, 6.5 vs 6.0, $p=0.024$ ), but the net decrease in Tegner score was equivalent among the two groups (median, 1.0 vs 1.0). The two groups had a similar flexion range $(p=0.174)$, with no extension deficits in either group $(p=0.915)$. A glide pivot-shift was observed in one patient $(3 \%)$ in the Lemaire group, but in none of the patients in the Reference group.

\section{Discussion}

The most important finding of this study was that ACLR with a modified Lemaire procedure for knees with rotational instability could provide similar isokinetic muscle recovery as does stand-alone ACLR in knees with 
Table 1 Demographics and preoperative data

\begin{tabular}{|c|c|c|c|c|c|}
\hline & \multicolumn{2}{|c|}{$\begin{array}{l}\text { Lemaire group } \\
n=35 \text { knees }\end{array}$} & \multicolumn{2}{|c|}{$\begin{array}{l}\text { Reference group } \\
n=52 \text { knees }\end{array}$} & \multirow[t]{3}{*}{$p$-value* } \\
\hline & \multicolumn{2}{|l|}{ n (\%) } & \multicolumn{2}{|l|}{ n (\%) } & \\
\hline & Mean \pm SD & Range & Mean \pm SD & Range & \\
\hline \multicolumn{6}{|l|}{ Demographics } \\
\hline Male sex & $28(80 \%)$ & & $29(56 \%)$ & & 0.021 \\
\hline Age (years) & $23.0 \pm 6.3$ & $(15-37)$ & $34.2 \pm 10.5$ & $(16-53)$ & $<0.001$ \\
\hline $\mathrm{BMI}\left(\mathrm{kg} / \mathrm{m}^{2}\right)$ & $23.5 \pm 2.5$ & $(20-29)$ & $23.9 \pm 2.7$ & $(18-31)$ & n.s. \\
\hline Tegner score** (pre-injury) & 7.5 & $(7-9)$ & 6.5 & $(7-9)$ & 0.001 \\
\hline \multicolumn{6}{|l|}{ Preoperative data } \\
\hline Lachman & & & & & n.s. \\
\hline Hard endpoint & $0(0 \%)$ & & $0(0 \%)$ & & \\
\hline Delayed hard endpoint & $0(0 \%)$ & & $4(8 \%)$ & & \\
\hline Soft endpoint & 35 (100\%) & & $48(92 \%)$ & & \\
\hline Pivot Shift & & & & & $<0.001$ \\
\hline None & $0(0 \%)$ & & $0(0 \%)$ & & \\
\hline Glide & $0(0 \%)$ & & $51(98 \%)$ & & \\
\hline Clunk & $32(91 \%)$ & & $0(0 \%)$ & & \\
\hline Gross & $3(9 \%)$ & & $0(0 \%)$ & & \\
\hline Lysholm score & $65.4 \pm 17.9$ & $(35-100)$ & $68.2 \pm 16.7$ & (34-99) & n.s. \\
\hline IKDC subjective score & $61.3 \pm 15.0$ & $(23-91)$ & $59.7 \pm 13.1$ & $(22-86)$ & n.s. \\
\hline Static ATT & $2.6 \pm 3.7$ & $(5-10)$ & $1.5 \pm 2.3$ & $(4-6)$ & n.s. \\
\hline Dynamic ATT (Differential laxity) & $7.9 \pm 3.9$ & $(0-17)$ & $5.9 \pm 3.6$ & $(3-14)$ & 0.022 \\
\hline Extension deficit & $1(3 \%)$ & & $1(2 \%)$ & & n.s. \\
\hline Flexion range & $135.4 \pm 13.7$ & $(60-140)$ & $133.4 \pm 7.5$ & $(115-140)$ & 0.022 \\
\hline
\end{tabular}

Abbreviations: BMI Body Mass Index, IKDC International Knee Documentation Committee, ATT Anterior Tibial Translation, Op Operated, Contra Contralateral *Fisher's exact test or Wilcoxon rank sum test; ${ }^{* *}$ Tegner score reported as Median and Interquartile range

minimal rotational instability. The hypothesis is therefore confirmed, suggesting that, for ACL-deficient knees with high-grade pivot-shift, a modified Lemaire procedure restores rotational stability without increasing isokinetic muscle deficit at the time of RTP.

In the present series, none of the patients had highgrade pivot-shift at 8 months following ACLR, and only one knee $(3 \%)$ in the Lemaire group had low-grade residual pivot-shift. This corroborates the findings of systematic reviews that found LET procedures to reduce pivot-shift, leading to greater rotational stability [21, 38]. Furthermore, this series had no graft failures in the Lemaire group, compared to 1 graft failure in the Reference group. This is in agreement with studies which found that a LET does not increase risks of graft failure $[37,42]$, and could in fact protect the graft in the early postoperative period by decreasing the forces on it by $43 \%$ and by addressing the residual instability as a risk for graft failure $[1,18]$.

The isokinetic strength deficits observed in the Lemaire group of this study are comparable to isokinetic strength deficits reported for stand-alone ACLR (without
LET) in the literature. Tashiro et al. [40] found, using lower angular velocities, a quadriceps deficit of $20 \%$ at $60 \%$, and $10 \%$ at $180 \%$ s. Yosmaoglu et al. [45] found quadriceps deficit of $18.3 \%$ at $60 \%$ s, and $15.3 \%$ at $180 \%$, and a hamstrings deficit $21.3 \%$ at $60 \%$ s, and $9.6 \%$ at $180^{\circ} / \mathrm{s}$. Kyung et al. [24] found, using semitendinosus and gracilis graft, quadriceps deficits of $29.9 \%$ at $60 \%$ and $18.5 \%$ at $180 \%$ s, and hamstrings deficits of $24.6 \%$ at $60^{\circ} / \mathrm{s}$ and $10.5 \%$ at $180^{\circ} / \mathrm{s}$.

Isokinetic evaluation of athletic patients is an integral part in the rehabilitation program and to validate RTP $[31,43,44]$. The findings of this study revealed similar isokinetic test outcomes at all speeds and modes, but a significant difference in the mixed $\mathrm{H} / \mathrm{Q}$ ratio $(p=0.011)$ (Table 3). Croisier et al. [10] advocate that mixed H/Q ratios are the most important since they closely represent real biomechanical conditions of athletes during contact sports, particularly actions such as sprinting and kicking.

The indications and techniques for extra-articular procedures during ACLR are constantly evolving [16]. Recently, several authors revised the indications for extra- 
Table 2 Intraoperative data

\begin{tabular}{|c|c|c|c|c|c|}
\hline & \multicolumn{2}{|c|}{$\begin{array}{l}\text { Lemaire group } \\
n=35 \text { knees }\end{array}$} & \multicolumn{2}{|c|}{$\begin{array}{l}\text { Reference group } \\
n=52 \text { knees }\end{array}$} & \multirow[t]{2}{*}{$p$-value* } \\
\hline & $\mathrm{n}$ & (\%) & $\mathrm{n}$ & $(\%)$ & \\
\hline Meniscal lesions & & & & & n.s. \\
\hline None & 16 & $(46 \%)$ & 20 & $(38 \%)$ & \\
\hline Isolated medial & 10 & $(29 \%)$ & 20 & $(38 \%)$ & \\
\hline Isolated lateral & 3 & $(9 \%)$ & 8 & $(15 \%)$ & \\
\hline Bicompartmental & 6 & $(17 \%)$ & 4 & (8\%) & \\
\hline Medial meniscal treatment & & & & & n.s. \\
\hline No lesion & 19 & $(54 \%)$ & 28 & $(54 \%)$ & \\
\hline Untreated & 0 & $(0 \%)$ & 2 & $(4 \%)$ & \\
\hline Resected & 2 & $(6 \%)$ & 5 & $(10 \%)$ & \\
\hline Sutured & 14 & $(40 \%)$ & 17 & $(33 \%)$ & \\
\hline Lateral meniscal treatment & & & & & n.s. \\
\hline No lesion & 26 & $(74 \%)$ & 40 & $(77 \%)$ & \\
\hline Untreated & 0 & $(0 \%)$ & 2 & $(4 \%)$ & \\
\hline Resected & 4 & $(11 \%)$ & 4 & (8\%) & \\
\hline Sutured & 5 & $(14 \%)$ & 6 & $(12 \%)$ & \\
\hline
\end{tabular}

Abbreviation: $A C L$ Anterior Cruciate Ligament

*Fisher's exact test

articular procedures to patients younger than 30 years or those with concomitant medial meniscus tears $[6,35]$. The biomechanical function and benefits of LET have been widely studied, demonstrating its role of limiting translation within the lateral compartment $[15,27,39$, 47], reducing pivot-shift [16, 30, 32, 47], and protecting the graft and meniscus $[17,18,30]$, with little or no side effects [36]. Some authors found that LET improves clinical outcomes $[27,34,46]$, while in this study, the postoperative functional outcomes are equivalent between the Lemaire group and Reference group, despite greater preoperative laxity $(p=0.022)$ and rotational instability $(p<0.001)$ in the Lemaire group (Table 1$)$.

The authors believe that the terminology used to describe extra-articular procedures should be reconsidered. This is because the general term 'lateral extra-articular tenodesis' could be misleading, as the procedure does not involve suturing the end of a tendon to a bone. The

Table 3 Isokinetic data

\begin{tabular}{|c|c|c|c|c|c|}
\hline & \multicolumn{2}{|c|}{$\begin{array}{l}\text { Lemaire group } \\
n=35 \text { knees }\end{array}$} & \multicolumn{2}{|c|}{$\begin{array}{l}\text { Reference group } \\
n=51 \text { knees }\end{array}$} & \multirow[t]{2}{*}{$p$-value* } \\
\hline & Mean \pm SD & Range & Mean \pm SD & Range & \\
\hline \multicolumn{6}{|l|}{ Concentric mode $240^{\circ} / \mathrm{s}$} \\
\hline Hamstrings deficit (\%) & $9.0 \pm 16.6$ & $(-47.0-34.3)$ & $10.9 \pm 16.6$ & $(-39.4-66.7)$ & n.s. \\
\hline Quadriceps deficit (\%) & $13.6 \pm 12.2$ & $(-21.9-45.6)$ & $18.2 \pm 13.4$ & $(-9.3-43.1)$ & n.s. \\
\hline \multicolumn{6}{|l|}{ Concentric mode $90^{\circ} / \mathrm{s}$} \\
\hline Hamstrings deficit (\%) & $9.0 \pm 13.6$ & $(-16.6-31.6)$ & $8.5 \pm 22.4$ & $(-63.4-85.3)$ & n.s. \\
\hline Quadriceps deficit (\%) & $12.2 \pm 15.9$ & $(-21.7-58.3)$ & $15.6 \pm 14.1$ & $(-15.9-46.7)$ & n.s. \\
\hline \multicolumn{6}{|l|}{ Eccentric mode $30 \%$} \\
\hline Hamstrings deficit (\%) & $12.0 \pm 17.1$ & $(-42.7-43.0)$ & $11.2 \pm 13.5$ & $(-15.0-45.4)$ & n.s. \\
\hline \multicolumn{6}{|l|}{ H/Q Ratios } \\
\hline Concentric $240^{\circ}$ & $0.64 \pm 0.15$ & $(0.41-1.14)$ & $0.66 \pm 0.15$ & $(0.19-1.16)$ & n.s. \\
\hline Concentric $90^{\circ}$ & $0.60 \pm 0.12$ & $(0.36-1.02)$ & $0.62 \pm 0.15$ & $(0.08-0.90)$ & n.s. \\
\hline Mixed $\dagger$ & $1.02 \pm 0.19$ & $(0.61-1.50)$ & $1.14 \pm 0.24$ & $(0.71-1.77)$ & 0.011 \\
\hline
\end{tabular}

Abbreviations: $H$ Hamstrings, $Q$ Quadriceps

*Wilcoxon rank sum test

tEccentric Hamstrings at $30 \% \mathrm{~s} \div$ Concentric Quadriceps at $240 \% \mathrm{~s}$ 
Table 4 Postoperative data

\begin{tabular}{|c|c|c|c|c|c|}
\hline & \multicolumn{2}{|c|}{$\begin{array}{l}\text { Lemaire group } \\
n=35 \text { knees }\end{array}$} & \multicolumn{2}{|c|}{$\begin{array}{l}\text { Reference group } \\
n=51 \text { knees }\end{array}$} & \multirow[t]{3}{*}{$p$-value* } \\
\hline & \multicolumn{2}{|l|}{ n (\%) } & \multicolumn{2}{|l|}{ n (\%) } & \\
\hline & Mean \pm SD & Range & Mean \pm SD & Range & \\
\hline \multicolumn{6}{|l|}{ Postoperative data } \\
\hline Lachman & & & & & 0.025 \\
\hline Hard endpoint & $33(94 \%)$ & & $51(100 \%)$ & & \\
\hline Delayed hard endpoint & $2(6 \%)$ & & $0(0 \%)$ & & \\
\hline Soft endpoint & $0(0 \%)$ & & $0(0 \%)$ & & \\
\hline Pivot Shift & & & & & n.s. \\
\hline None & 34 (97\%) & & $51(100 \%)$ & & \\
\hline Glide & $1(3 \%)$ & & $0(0 \%)$ & & \\
\hline Clunk & $0(0 \%)$ & & $0(0 \%)$ & & \\
\hline Gross & $0(0 \%)$ & & $0(0 \%)$ & & \\
\hline Complications & $0(0 \%)$ & & $1(2 \%)$ & & n.s. \\
\hline Tegner score ${ }^{* *}$ & 6.5 & $(6-8)$ & 6.0 & $(5-7)$ & 0.024 \\
\hline Lysholm & $90.2 \pm 12.1$ & $(34-100)$ & $90.1 \pm 6.2$ & $(75-100)$ & n.s. \\
\hline IKDC subjective score & $88.4 \pm 11.6$ & $(39-100)$ & $85.9 \pm 8.8$ & (59-98) & n.s. \\
\hline ACL-RSI & $77.1 \pm 14.5$ & (33-96) & $78.7 \pm 11.5$ & $(42-98)$ & n.s. \\
\hline Extension deficit & $0(0 \%)$ & & $2(4 \%)$ & & n.s. \\
\hline Flexion range & $137.6 \pm 3.7$ & $(130-140)$ & $136.1 \pm 5.7$ & $(115-140)$ & n.s. \\
\hline \multicolumn{6}{|l|}{ Net change } \\
\hline Tegner score ${ }^{* *}$ & -1.0 & $(-2-0)$ & -1.0 & $(-2-0)$ & n.s. \\
\hline Lysholm & $24.8 \pm 20.0$ & $(30-60)$ & $22.3 \pm 17.5$ & $(14-57)$ & n.s. \\
\hline IKDC subjective score & $27.1 \pm 18.7$ & $(24-72)$ & $26.4 \pm 13.1$ & $(1-53)$ & n.s. \\
\hline
\end{tabular}

Abbreviations: IKDC International Knee Documentation Committee, ACL-RSI Anterior Cruciate Ligament Return to Sport after Injury

*Fisher's exact test or Wilcoxon rank sum test; ${ }^{* *}$ Tegner score reported as Median and Interquartile range

term 'lateral extra-articular plasty' better describes the moulding of the tensor fascia latae, which is not a tendon, and therefore exhibits more elastic properties.

This study has several limitations which must be taken into account. The number of patients in each cohort was small, and due to the specific indications for a Lemaire procedure, the demographics were not equivalent; the Lemaire group was 10 years younger, had a greater proportion of males and higher Tegner scores. Younger patients are typically more active and potentially more motivated to return to activity. As Tegner score was significantly different, it was opted to compare the isokinetic strength deficits instead of the absolute strength. A control group of patients with severe rotational knee instability was not included because of the indications for a Lemaire procedure. Furthermore, the groups also differed in meniscal lesions and treatments. In addition, isokinetic deficits were tested at $240 \%$ s and $90^{\circ} / \mathrm{s}$, validated by Burgi et al. [4] and Undheim et al. [43], while most studies used $180^{\circ} / \mathrm{s}$ and $60^{\circ} / \mathrm{s}$. Nevertheless, this study has several strengths, including the consistency of surgical technique and graft type, as well as being the first to investigate the effect of a Lemaire procedure on isokinetic muscle recovery.

\section{Conclusion}

ACLR with a modified Lemaire procedure for knees with rotational instability grants equivalent isokinetic muscle recovery as does stand-alone ACLR in knees with no rotational instability. For ACL-deficient knees with highgrade pivot-shift, a modified Lemaire procedure restores rotational stability without compromising isokinetic muscle recovery at the time of return-to-play.

\section{Supplementary Information}

The online version contains supplementary material available at https://doi. org/10.1186/s40634-020-00302-1.

\section{Additional file 1.}

\section{Acknowledgements}

The authors are grateful to Luca Nover for assisting with manuscript preparation. 


\section{Authors' contributions}

L: study design, data collection, manuscript editing. GD: study design, data collection. TC: data collection, manuscript editing. AS: data collection, manuscript approval. AG: data collection, manuscript approval. FVR: literature review, data interpretation, figures and tables, manuscript writing. MS: study design, data interpretation, manuscript editing, coordination and supervision. DD: study design, data collection, manuscript editing, coordination and supervision. The authors read and approved the final manuscript.

\section{Funding}

The authors are grateful to Ramsay Santé for funding statistical analysis and manuscript preparation.

\section{Availability of data and materials}

Data are available upon reasonable request.

\section{Ethics approval and consent to participate}

All patients provided written informed consent for the use of their data for research and publishing purposes. This study was approved by the Conseil d'Orientation Scientifique Ramsay Santé (IORG0009085) with reference: COSRGDS-2020-03-006-DEJOUR-D.

\section{Consent for publication}

Not applicable.

\section{Competing interests}

Dr. Dejour reports personal fees from SBM, during the conduct of the study.

\section{Author details}

'Lyon-Ortho-Clinic, Clinique de la Sauvegarde, Ramsay Santé, 29 Avenue des Sources, 69009 Lyon, France. ${ }^{2}$ Sports Physiotherapy Centre, Lyon-Ortho-Clinic, Clinique de la Sauvegarde, 29 Avenue des Sources, 69009 Lyon, France. ${ }^{3}$ Hôpital de la Croix-Rousse, Université Lyon 1, 103 Grande Rue de la Croix-Rousse, 69004 Lyon, France. ${ }^{4}$ ReSurg SA, Rue Saint Jean 22, 1260 Nyon, Switzerland.

Received: 16 October 2020 Accepted: 21 October 2020 Published online: 30 October 2020

\section{References}

1. Batty L, Lording T (2018) Clinical results of lateral extra-articular Tenodesis. Tech Orthop 33(4):232-238

2. Bodkin SG, Rutherford MH, Diduch DR, Brockmeier SF, Hart JM (2020) How much time is needed between serial "return to play" assessments to achieve clinically important strength gains in patients recovering from anterior cruciate ligament reconstruction? Am J Sports Med 48(1):70-77

3. Bohu Y, Klouche S, Lefevre N, Webster K, Herman S (2015) Translation, crosscultural adaptation and validation of the French version of the anterior cruciate ligament-return to sport after injury (ACL-RSI) scale. Knee Surg Sports Traumatol Arthrosc 23(4):1192-1196

4. Burgi CR, Peters S, Ardern CL, Magill JR, Gomez CD, Sylvain J, Reiman MP (2019) Which criteria are used to clear patients to return to sport after primary ACL reconstruction? A scoping review. Br J Sports Med 53(18): 1154-1161

5. Cavaignac E, Wytrykowski K, Reina N, Pailhe R, Murgier J, Faruch M, Chiron P (2016) Ultrasonographic identification of the anterolateral ligament of the knee. Arthroscopy 32(1):120-126

6. Cerciello S, Batailler C, Darwich N, Neyret P (2018) Extra-articular Tenodesis in combination with anterior cruciate ligament reconstruction: an overview. Clin Sports Med 37(1):87-100

7. Christel P, Djian P (2002) Anterio-lateral extra-articular tenodesis of the knee using a short strip of fascia lata. Rev Chir Orthop Reparatrice Appar Mot 88(5):508-513

8. Claes S, Vereecke E, Maes M, Victor J, Verdonk P, Bellemans J (2013) Anatomy of the anterolateral ligament of the knee. J Anat 223(4):321-328

9. Cooper DE, Arnoczky SP, Warren RF (1990) Arthroscopic meniscal repair. Clin Sports Med 9(3):589-607

10. Croisier JL, Forthomme B, Namurois MH, Vanderthommen M, Crielaard JM (2002) Hamstring muscle strain recurrence and strength performance disorders. Am J Sports Med 30(2):199-203
11. Croisier JL, Ganteaume S, Binet J, Genty M, Ferret JM (2008) Strength imbalances and prevention of hamstring injury in professional soccer players: a prospective study. Am J Sports Med 36(8):1469-1475

12. Dejour D, La Barbera G, Pasqualotto S, Valoroso M, Nover L, Reynolds R, Saffarini M (2017) Sagittal plane corrections around the knee. J Knee Surg 30(8):736-745

13. Dejour D, Ntagiopoulos PG, Saggin PR, Panisset JC (2013) The diagnostic value of clinical tests, magnetic resonance imaging, and instrumented laxity in the differentiation of complete versus partial anterior cruciate ligament tears. Arthroscopy 29(3):491-499

14. Dejour D, Pungitore M, Valluy J, Nover L, Saffarini M, Demey G (2019) Tibial slope and medial meniscectomy significantly influence short-term knee laxity following ACL reconstruction. Knee Surg Sports Traumatol Arthrosc 27(11):3481-3489

15. Dejour D, Vanconcelos W, Bonin N, Saggin PR (2013) Comparative study between mono-bundle bone-patellar tendon-bone, double-bundle hamstring and mono-bundle bone-patellar tendon-bone combined with a modified Lemaire extra-articular procedure in anterior cruciate ligament reconstruction. Int Orthop 37(2):193-199

16. Dodds AL, Gupte CM, Neyret P, Williams AM, Amis AA (2011) Extra-articular techniques in anterior cruciate ligament reconstruction: a literature review. J Bone Joint Surg Br 93(11):1440-1448

17. Draganich LF, Reider B, Ling M, Samuelson M (1990) An in vitro study of an intraarticular and extraarticular reconstruction in the anterior cruciate ligament deficient knee. Am J Sports Med 18(3):262-266

18. Engebretsen L, Lew WD, Lewis JL, Hunter RE (1990) The effect of an iliotibial tenodesis on intraarticular graft forces and knee joint motion. Am J Sports Med 18(2):169-176

19. Getgood A, Brown C, Lording T, Amis A, Claes S, Geeslin A, MusahI V (2019) The anterolateral complex of the knee: results from the international ALC consensus group meeting. Knee Surg Sports Traumatol ArthrosC 27(1):166-176

20. Hetsroni I, Wiener Y, Ben-Sira D, lacono AD, Marom N, van Stee M, Ayalon M (2020) Symmetries in muscle torque and landing kinematics are associated with maintenance of sports participation at 5 to 10 years after ACL reconstruction in young men. Orthop J Sports Med 8(6): 2325967120923267

21. Hewison CE, Tran MN, Kaniki N, Remtulla A, Bryant D, Getgood AM (2015) Lateral extra-articular Tenodesis reduces rotational laxity when combined with anterior cruciate ligament reconstruction: a systematic review of the literature. Arthroscopy 31(10):2022-2034

22. Imbert P, Lutz C, Daggett M, Niglis L, Freychet B, Dalmay F, Sonnery-Cottet $B$ (2016) Isometric characteristics of the anterolateral ligament of the knee: a cadaveric navigation study. Arthroscopy 32(10):2017-2024

23. Irrgang JJ, Anderson AF, Boland AL, Harner CD, Kurosaka M, Neyret $P$, Richmond JC, Shelborne KD (2001) Development and validation of the international knee documentation committee subjective knee form. Am J Sports Med 29(5):600-613

24. Kyung HS, Lee HJ, Oh CW, Hong HP (2015) Comparison of results after anterior cruciate ligament reconstruction using a four-strand single semitendinosus or a semitendinosus and gracilis tendon. Knee Surg Sports Traumatol Arthrosc 23(11):3238-3243

25. Legnani C, Boisio F, Borgo E, Ventura A (2019) Autograft for anterior cruciate ligament revision surgery : lateral extra-articular tenodesis in skeletally mature patients under 25 years of age. Orthopade 48(10):858-861

26. Lemaire M (1975) Chronic knee instability. Technics and results of ligament plasty in sports injuries. J Chir (Paris) 110(4):281-294

27. Lerat $J$, Chotel F, Besse JL, Moyen B, Binet G, Craviari T, Brunet-Guedj $E_{i}$ Adeleine P, Nemoz JC (1998) The results after 10-16 years of the treatment of chronic anterior laxity of the knee using reconstruction of the anterior cruciate ligament with a patellar tendon graft combined with an external extra-articular reconstruction. Rev Chir Orthop Reparatrice Appar Mot 84(8): $712-727$

28. Lysholm J, Gillquist J (1982) Evaluation of knee ligament surgery results with special emphasis on use of a scoring scale. Am J Sports Med 10(3):150-154

29. Maffiuletti NA, Bizzini M, Desbrosses K, Babault N, Munzinger U (2007) Reliability of knee extension and flexion measurements using the con-Trex isokinetic dynamometer. Clin Physiol Funct Imaging 27(6):346-353

30. Marcacci M, Zaffagnini S, Giordano G, lacono F, Presti ML (2009) Anterior cruciate ligament reconstruction associated with extra-articular tenodesis: a 
prospective clinical and radiographic evaluation with 10- to 13-year followup. Am J Sports Med 37(4):707-714

31. Mikkelsen C, Werner S, Eriksson E (2000) Closed kinetic chain alone compared to combined open and closed kinetic chain exercises for quadriceps strengthening after anterior cruciate ligament reconstruction with respect to return to sports: a prospective matched follow-up study. Knee Surg Sports Traumatol Arthrosc 8(6):337-342

32. Monaco E, Labianca L, Conteduca F, De Carli A, Ferretti A (2007) Double bundle or single bundle plus extraarticular tenodesis in $\mathrm{ACL}$ reconstruction? A CAOS study. Knee Surg Sports Traumatol Arthrosc 15(10):1168-1174

33. Neri T, Parker DA, Beach A, Boyer B, Farizon F, Philippot R (2018) Anterolateral ligament of the knee: what we know about its anatomy, histology, biomechanical properties and function. Surg Technol Int 33:312-318

34. Noyes FR (2016) Editorial commentary: lateral extra-articular reconstructions with anterior cruciate ligament surgery: are these operative procedures supported by in vitro biomechanical studies? Arthroscopy 32(12):2612-2615

35. Ntagiopoulos P, Dejour D (2018) Extra-articular Plasty for revision anterior cruciate ligament reconstruction. Clin Sports Med 37(1):115-125

36. Panisset JC, Pailhe R, Schlatterer B, Sigwalt L, Sonnery-Cottet B, Lutz C, Lustig S, Batailler C, Bertiaux S, Ehkirch FP, Colombet P, Steltzlen C, Louis ML, D'Ingrado P, Dalmay F, Imbert P, Saragaglia D (2017) Short-term complications in intra- and extra-articular anterior cruciate ligament reconstruction. Comparison with the literature on isolated intra-articular reconstruction. A multicenter study by the French Arthroscopy Society. Orthop Traumatol Surg Res 103(8s):S231-s236

37. Rezende FC, de Moraes WY, Martimbianco AL, Luzo MV, da Silveira Franciozi CE, Belloti JC (2015) Does combined intra- and Extraarticular ACL reconstruction improve function and stability? A meta-analysis. Clin Orthop Relat Res 473(8):2609-2618

38. Song GY, Hong L, Zhang H, Zhang J, Li Y, Feng H (2016) Clinical outcomes of combined lateral extra-articular Tenodesis and intra-articular anterior cruciate ligament reconstruction in addressing high-grade pivot-shift phenomenon. Arthroscopy 32(5):898-905

39. Sonnery-Cottet B, Vieira TD, Ouanezar H (2019) Anterolateral ligament of the knee: diagnosis, indications, technique, outcomes. Arthroscopy 35(2):302-303

40. Tashiro T, Kurosawa H, Kawakami A, Hikita A, Fukui N (2003) Influence of medial hamstring tendon harvest on knee flexor strength after anterior cruciate ligament reconstruction. A detailed evaluation with comparison of single- and double-tendon harvest. Am J Sports Med 31(4):522-529

41. Tegner Y, Lysholm J (1985) Rating systems in the evaluation of knee ligament injuries. Clin Orthop Relat Res 198:43-49

42. Trojani C, Beaufils P, Burdin G, Bussiere C, Chassaing V, Djian P, Dubrana F, Ehkirch FP, Franceschi JP, Hulet C, Jouve F, Potel JF, Sbihi A, Neyret P, Colombet P (2012) Revision ACL reconstruction: influence of a lateral tenodesis. Knee Surg Sports Traumatol Arthrosc 20(8):1565-1570

43. Undheim MB, Cosgrave C, King E, Strike S, Marshall B, Falvey E, FranklynMiller A (2015) Isokinetic muscle strength and readiness to return to sport following anterior cruciate ligament reconstruction: is there an association? A systematic review and a protocol recommendation. Br J Sports Med 49(20):1305-1310

44. van Melick N, van Cingel RE, Brooijmans F, Neeter C, van Tienen T, Hullegie W, Nijhuis-van der Sanden MW (2016) Evidence-based clinical practice update: practice guidelines for anterior cruciate ligament rehabilitation based on a systematic review and multidisciplinary consensus. $\mathrm{Br} J$ Sports Med 50(24):1506-1515

45. Yosmaoglu HB, Baltaci G, Ozer H, Atay A (2011) Effects of additional gracilis tendon harvest on muscle torque, motor coordination, and knee laxity in ACL reconstruction. Knee Surg Sports Traumatol ArthrosC 19(8):1287-1292

46. Zaffagnini S, Marcacci M, Lo Presti M, Giordano G, lacono F, Neri MP (2006) Prospective and randomized evaluation of $A C L$ reconstruction with three techniques: a clinical and radiographic evaluation at 5 years follow-up. Knee Surg Sports Traumatol Arthrosc 14(11):1060-1069

47. Zaffagnini S, Signorelli C, Bonanzinga T, Roberti Di Sarsina T, Grassi A, Budeyri A, Marcheggiani Muccioli GM, Raggi F, Bragonzoni L, Lopomo N, Marcacci M (2016) Technical variables of ACL surgical reconstruction: effect on post-operative static laxity and clinical implication. Knee Surg Sports Traumatol Arthrosc 24(11):3496-3506

\section{Publisher's Note}

Springer Nature remains neutral with regard to jurisdictional claims in published maps and institutional affiliations.

\section{Submit your manuscript to a SpringerOpen ${ }^{\circ}$ journal and benefit from:}

- Convenient online submission

- Rigorous peer review

- Open access: articles freely available online

High visibility within the field

- Retaining the copyright to your article

Submit your next manuscript at $\boldsymbol{\nabla}$ springeropen.com 